\title{
A EDUCAÇÃO APESAR DA DIFERENÇA
}

CDD: 370.1

\section{THE EDUCATION DESPITE THE DIFFERENCE}

\section{Gabriela Gomes Costardi ${ }^{1}$}

\begin{abstract}
Resumo
Este artigo abordará as concepções presentes na obra de Freud a respeito da educação, sob o enfoque da relação desta com a diferença. A educação foi tratada por ele, tanto a partir de uma proposta de profilaxia das neuroses quanto numa proposta de renúncia pulsional, e pretendemos pensar sobre as consequências que podem ser extraídas dessas posições, tendo como centro da reflexão o conceito de pulsão de morte. Nessa perspectiva, lançaremos mão de conceitos da psicanálise lacaniana para debater a questão da diferença, numa referência à problemática das relações entre linguagem e real. Retomaremos brevemente o percurso de Lacan, desde a primazia do simbólico até a formulação do conceito de objeto, para, então, problematizarmos a diferença a partir dos diversos laços sociais propostos por ele.
\end{abstract}

Palavras-chave: Educação. Diferença. Psicanálise. Repressão.

\begin{abstract}
This article will deal with current concepts in the work of Freud regarding education, under the focus of its relation with differences. Education was dealt by Freud through the perspective of neurosis prophylaxis and pulsional renounce. The aim here is to reflect on the consequences which can arise from these perspectives, having the pulse of death at the core of the reflection. In this sense, we are going to analyze the concepts of Lacanian psychoanalysis to debate the question of difference, regarding the problematic relations between language and reality. We will briefly retake Lacan's journey, since the primacy of the symbolic until the formulation of the concept of object. We will then problematize the differences through the various social bonds proposed by him.
\end{abstract}

Keywords: Education. Difference. Psychoanalysis. Repression.

\section{PARA COMEÇAR}

Educar é uma tarefa que se marca pela especificidade de seu objeto, o humano. Visa a modificar algo do humano. O que exatamente visa a modificar? Com quais objetivos? A partir de que meios? Estas são questões mais expostas à variação. Não varia a

\footnotetext{
${ }^{1}$ Psicanalista, Mestre em Educação pela Unicamp e doutoranda em Psicologia Escolar e do Desenvolvimento Humano pela USP. E-mail: gabicostardi@ hotmail.com - São Paulo, SP, Brasil.
} 
noção de incidir sobre o homem, imprimir-lhe marcas, delimitar sua expansão, permitir-lhe aquisições.

Freud pensou sobre a educação, e não de forma homogênea: houve movimento em sua obra, uma variação drástica, até. Para pensar suas posições sobre educação, a partir da noção de diferença, será preciso recorrer a outros conceitos estabelecidos por ele, formulando relações que não são evidentes, e, por isso, nos exigirão um tanto de criação e de risco.

\section{AVANÇANDO}

Como definir a especificidade do humano, para colocá-lo em relação à educação? O ponto de partida é que há algo além do biológico; o ser humano ultrapassa a condição de integração ao natural do seu corpo e do ambiente. Não podemos contar com instintos que, diante de suas próprias demandas, oferecerão os meios de satisfazê-las; ficamos desnaturados, tendo que dar destinos aos apelos que nossa condição nos impõe.

Para pensar sobre esse além da natureza, um recurso que desponta de saída é a questão do atravessamento da linguagem, da cultura, sobre o real da biologia. O homem, enquanto ser simbólico, mediatizado pelo signo, produtor de sentido. Para a psicanálise, isso é insuficiente. $\mathrm{O}$ estatuto da representação na psicanálise enviesa a noção do símbolo enquanto aquilo que se interpõe entre um objeto do mundo externo e o sujeito, no sentido de permitir ao sujeito internalizar um objeto de fora pelo estabelecimento de um representante psíquico. Há um nível da representação que compõe a realidade pulsional do sujeito. É aqui que a concepção da psicanálise sobre o humano ganha especificidade.

Portanto, é no conceito de pulsão que apostaremos para refletir sobre a educação a partir da psicanálise. Para isso, faremos uma pequena digressão em direção à teoria.

De início, o ser humano tem um corpo, esse corpo necessita de estímulos, é animado por eles. Tomemos o exemplo da fome. A fome traz dor e faz o bebê se manifestar. Então, um outro (na função materna) lhe oferece o alimento; e mais: lhe oferece palavras e também um ritual de investimento afetivo. $O$ pequeno experimenta a satisfação física de saciar a fome e também um prazer a mais. Daí que ele deseje repetir essa experiência não apenas pela satisfação física, mas também por esse prazer, no qual Freud 
reconheceu a qualidade do sexual. Toda a mucosa da boca, os dentes, os lábios vão sendo erotizados para e pela obtenção do prazer, e o estímulo, que originalmente se devia à fome e tinha o objeto alimento como correlato, passa por uma complexização, pois dá lugar a um afeto que será apreendido a partir de um representante, não sendo imediato, puro. É dessa forma que a necessidade biológica dará suporte à instalação da pulsão oral, quando a apreensão da afetação que tem lugar no corpo passa pela linguagem.

Isso aponta para o fato de que a pulsão não foi tratada por Freud como algo unitário, uma substância homogênea, mas como uma composição de dois elementos: um representacional e um energético. É importante pensar que esse tipo de representação não é da ordem da lógica simbólica, de aquisição psicogenética; designa apenas algo que ultrapassa o orgânico, se reproduz num plano intermediário entre soma e psique.

Além do conceito de pulsão, há um outro pilar que sustenta a psicanálise: a noção de inconsciente. Trataremos aqui do inconsciente enquanto instância psíquica, formada pelo material recalcado. Interessa-nos especificar que o processo de recalcamento é estabelecido por uma censura exercida pelo próprio aparelho psíquico, daí o papel dos valores morais e dos ideais internalizados pelo sujeito.

Então, temos que a censura incide sobre a pulsão, mas não sobre seu quantum afetivo; apenas sobre seu elemento representacional. Assim, o fator energético se desliga da representação, podendo tomar três caminhos: ou é totalmente suprimido, o que se constata no caso da conversão histérica; ou se transforma em ansiedade, já que está desligado de sua representação; ou se liga a uma outra representação permitida pela consciência, ou seja, fica mais ou menos disfarçado. "Em primeiro lugar, pode ocorrer que um impulso afetivo ou emocional seja sentido, mas mal interpretado. Devido à repressão de seu representante adequado é forçado a ligar-se a outra idéia, sendo então considerado pela consciência como manifestação dessa idéia" (FREUD, 1915, p. 203-204).

Disso temos consequências: o ser do sujeito é constituído por afeto, quantum energético, e a linguagem tem uma materialidade que incide sobre seu corpo. Assim, podemos definir o processo educativo, genericamente, como essa operação da linguagem sobre os destinos pulsionais do sujeito. Mais especificamente, essa operação educativa tem um sentido: inserir um elemento de realidade diante da exigência incondicional de satisfação pulsional, moderá-la, dirigi-la, conciliá-la. 
Freud dialogou com essa concepção de educação e a tomou de diferentes perspectivas. Elegeremos duas de suas posições, temporalmente afastadas, que nos parecem emblemáticas. A primeira data de 1913 e está no texto o Interesse científico da psicanálise; sua proposta é de que a educação seja psicanaliticamente esclarecida.

Quando os educadores se familiarizarem com as descobertas da psicanálise, será mais fácil se reconciliarem com certas fases do desenvolvimento infantil e, entre outras coisas, não correrão o risco de superestimar a importância dos impulsos instintivos socialmente imprestáveis ou perversos que surgem nas crianças. Pelo contrário, vão se abster de qualquer tentativa de suprimir esses impulsos pela força, quando aprenderem que esforços desse tipo com freqüência produzem resultados não menos indesejáveis que a alternativa, tão temida pelos educadores, de dar livre trânsito às travessuras das crianças. A supressão forçada de fortes instintos por meios externos nunca produz, numa criança o efeito de esses instintos se extinguirem ou ficarem sob controle; conduz à repressão, que cria uma predisposição a doenças nervosas no futuro. A psicanálise tem freqüentes oportunidades de observar o papel desempenhado pela severidade inoportuna e sem discernimento da educação na produção de neuroses, ou o preço, em perda de eficiência e capacidade de prazer, que tem de ser pago pela normalidade na qual o educador insiste. E a psicanálise também pode demonstrar que preciosas contribuições para a formação do caráter são realizadas por esses instintos associais e perversos na criança, se não forem submetidos à repressão, e sim desviados de seus objetivos originais para outros mais valiosos, através do processo conhecido como "sublimação". Nossas mais elevadas virtudes desenvolveram-se, como formações reativas e sublimações, de nossas piores disposições. A educação deve escrupulosamente abster-se de soterrar essas preciosas fontes de ação e restringir-se a incentivar os processos pelos quais essas energias são conduzidas ao longo de trilhas seguras. Tudo o que podemos esperar a título de profilaxia das neuroses do indivíduo se encontra nas mãos de uma educação psicanaliticamente orientada. (FREUD, 1913, p. 225-226)

Algumas marcações sobre esse belo trecho. Freud está em plena formulação da teoria das neuroses enquanto produto do recalcamento das pulsões. Ele se coloca otimista quanto a futuras gerações que possam receber um apelo externo menos intenso no tocante à censura dos impulsos eróticos e agressivos. A ideia de profilaxia das neuroses é central aqui - é isso que o esclarecimento da psicanálise pode oferecer à prática educativa. Vemos, também, que sua preocupação se volta para apenas um sentido: condenar a censura imposta pela educação ao sujeito. É claro que ele não propõe que haja livre curso das exigências pulsionais, mas aposta que a transformação dessas exigências em outras mais elaboradas é suficiente para compor o processo educativo, o qual não precisaria passar pela repressão.

De saída, ficamos com a impressão de que essa posição inicial permite o acolhimento daquilo que, no sujeito, escapa a uma norma. É interessante pensar que não 
haveria um ideal - do qual todo desvio seria matéria de censura - para nortear a ação dos educadores. A proposta é de um acolhimento dessa "natureza instintual" do sujeito e, a partir daí, um incentivo para o estabelecimento de novos destinos à sua agressividade ou sexualidade, o que sugere um espaço para a produção de uma diferença.

O fato é que Freud avança em suas investigações e começa a recuar diante dessa prescrição sobre a necessidade de retirar a censura do ato educativo. Ele passa a tomar a constituição de um sujeito civilizado, enquanto um processo vivido numa tensão entre satisfação e renúncia pulsional, dentro do qual postula como necessário o caráter repressivo do meio externo. É essa a grande discussão que ele empreende em dois de seus grandes trabalhos: O futuro de uma ilusão (1927) e O mal-estar na civilização (1930).

\footnotetext{
Pensar-se-ia ser possível um reordenamento das relações humanas, que removeria as fontes de insatisfação para com a civilização pela renúncia à coerção e à repressão dos instintos, de sorte que, imperturbados pela discórdia interna, os homens pudessem dedicar-se à aquisição da riqueza e à sua fruição. Essa seria a idade de outro, mas é discutível se tal estado de coisas pode ser tornado realidade. Parece, antes, que toda civilização tem de se erigir sobre a coerção e a renúncia ao instinto; sequer parece certo se, caso cessasse a coerção, a maioria dos seres humanos estaria preparada para empreender o trabalho necessário à aquisição de novas riquezas. (FREUD, 1927, p. 17)
}

Neste momento de sua obra, já vemos que há uma preocupação relativa à medida da censura. É certo que não é indicado remover toda a felicidade do sujeito, a qual se baseia num tanto de realização de seus desejos. Daí só poderá advir a doença neurótica. Mas também não é possível esperar que aquilo de que os indivíduos espontaneamente se dispõem a abdicar de sua própria satisfação seja suficiente para constituir algo parecido com uma civilização. Na verdade, há algo de irreconciliável entre o individual e o coletivo. Compor um grupo é uma possibilidade a ser conquistada pelos indivíduos, e não uma competência previamente garantida pelo fato de ser humano.

A partir dessas reflexões, introduziremos uma segunda posição de Freud sobre a educação, enunciada na Conferência XXXIV, das Novas conferências introdutórias sobre psicanálise (1933): 
Vamos tornar claro para nós mesmos qual a tarefa primeira da educação. A criança deve aprender a controlar seus instintos. É impossível conceder-lhe liberdade de pôr em prática todos os seus impulsos sem restrição. [...] Por conseguinte, a educação deve inibir, proibir e suprimir, e isto ela procurou fazer em todos os períodos da história. Na análise, porém, temos verificado que precisamente essa supressão dos instintos envolve o risco de doença neurótica. [...] Assim, a educação tem de escolher seu caminho entre o Sila da nãointerferência e o Caríbdis da frustração. A menos que o problema seja inteiramente insolúvel, deve-se descobrir um ponto ótimo que possibilite à educação atingir o máximo com o mínimo de dano. Será, portanto, uma questão de decidir quanto proibir, em que hora e por que meios. E, ademais, devemos levar em conta o fato de que os objetos de nossa influência educacional têm disposições constitucionais inatas muito diferentes, de modo que é quase impossível que o mesmo método educativo possa ser uniformemente bom para todas as crianças. (FREUD, 1933, p. 82-83)

Salta aos olhos a distância em relação à primeira posição. A dimensão restritiva é recuperada com força, e ele deixa de lado o tom de aconselhar os educadores a abrir mão da censura. Freud agora coloca um problema: a educação precisa cumprir com um papel de repressão, mas para tal não há uma medida ótima predefinida. Como fazê-lo em cada caso, sabendo que há variações entre os indivíduos que a receberão? Daí, abre-se uma dimensão de singularidade no processo educativo e, sobretudo, uma dimensão ética, pois o educador não age por uma prescrição, mas a partir de uma decisão. Ele precisa escolher como conduzir sua tarefa e se responsabilizar pelas consequências desta.

É inquietante pensar nessa mudança tão expressiva. Por que Freud, ao avançar em seus estudos, parece adotar uma posição tão mais reacionária que a primeira? A psicanálise estaria na contramão das ideias de liberdade e pluralidade adotadas pelas posturas mais avançadas em educação?

O sentido dessa mudança precisa ser buscado no movimento da obra freudiana. É importante lembrar que, entre esses dois momentos-chave, houve uma virada em seu ensino: a postulação da pulsão de morte, em 1920, no texto Além do princípio do prazer. Freud sempre trabalhou com a ideia de conflito pulsional e postulou diversos pares pulsionais para dar conta desse modelo de movimento conflitivo. Sua versão última constituiu-se no par pulsão de vida e pulsão de morte. A grande mudança refere-se ao fato de ele ultrapassar a visão de que a natureza pulsional do homem se presta a preservar sua saúde e sua sobrevivência, o que é abarcado pelo princípio do prazer. Nessa visão inicial, o prazer está dado pela manutenção da homeostase do aparelho psíquico, e tudo o que se 
opõe a isso seria, por princípio, corrigido; ou seja, qualquer sofrimento seria recusado pelo ser humano. Ao sair desse paradigma, Freud reconhece casos em que o homem se coloca em direção à destrutividade e à morte, contrariando uma suposta tendência à preservação; e dá ao impulso para a morte tanta importância, para a dinâmica psíquica do sujeito, quanto ao impulso para a vida. Com a exacerbação da tendência à destrutividade da pulsão, nada mais sensato do que a necessidade de uma contenção externa, a qual, ao longo do desenvolvimento, será internalizada pelo indivíduo, para que ele mesmo defina contornos para sua satisfação.

Freud está propondo que não há uma saída por fora da neurose, o sujeito precisa enfrentar esse paradoxo para se constituir: há que fazer referência a uma autoridade externa, há que internalizar a censura, há que estabelecer ideais. Ou seja, o estabelecimento do desejo não se dá fora da lei, ele necessita dela. A constituição do singular em termos de satisfação pulsional deriva da constituição e do ultrapassamento dessas referências iniciais, e não da supressão delas.

Como pensar a diferença neste segundo momento? Ela se apresenta no espaço que se coloca entre a ação educativa e a resposta do sujeito a ela, já que este não é passivo, mas, ao contrário, faz suas escolhas e recusas.

Diríamos, então, que a diferença se impõe: dela não se escapa, a questão é se ela será segregada ou movimentará invenções.

A noção de diferença, aqui, tem uma especificidade, e precisamos debatê-la. Em linhas gerais, trata-se de que a linguagem não coincide com o real, aponta que há um resto da operação de significação. Ou seja, o estabelecimento do símbolo não abarca o todo da experiência humana. Para além dele, escapa algo que continua tendo um efeito sobre o sujeito. Isso diz do fato de que os ditos, os mandos, os combinados que se fazem num processo de educação não são seguidos por cada sujeito sem ruídos. Cada um faz alguma coisa daquilo que o processo educativo propõe, e é nisso que a diferença se expressa.

É importante compreender que isso que está fora da linguagem possui uma natureza heterogênea a ela, pertencendo ao que foi designado por Lacan como real, em oposição ao simbólico. Em uma aproximação da pulsão freudiana - composta por afeto e representação -, dizemos que esse resto fica do lado do afeto, da satisfação, da libido. Para pensar essa questão, lançaremos mão de alguns conceitos da psicanálise lacaniana, na 
medida em que Lacan propõe que esse rastro do real instala uma heterogeneidade nas relações humanas, e, para dar conta disso, se estabelece o laço social.

A formulação conceitual dos laços sociais, também chamados de discursos, se deu num momento avançado do ensino lacaniano. Inicialmente, ele trabalhou somente com a dimensão simbólica do homem. Apenas a partir do seminário 10 Lacan começou a teorizar sobre esse campo que está fora da linguagem, o que ele fez naquele momento pela inserção do conceito de objeto $a$. A ideia de que esse elemento do real recebe um certo tratamento pelo estabelecimento do laço social, ou do discurso, é trabalhada apenas a partir do seminário 17. Retomaremos esse percurso, em linhas gerais.

No primeiro momento, Lacan se dedicou a reler Freud a partir do conceito de significante. Sua intenção era recuperar o lugar central da palavra em sua relação com o inconsciente e demonstrar que o sujeito depende de uma estrutura que preexiste a ele, sendo efeito do jogo de significantes. Ou seja, ele queria retirar o eu, enquanto enunciador de significados, do centro da experiência analítica, para abordar o sujeito do inconsciente determinado pelas leis da linguagem, a saber, metáfora e metonímia. Nesse momento, tudo o que se dizia do inconsciente é que ele era estruturado como uma linguagem, do ponto de vista das leis que acabamos de citar, em que os significantes se encadeiam e se combinam à revelia do controle do sujeito, mas, ao contrário, tendo como efeito o próprio sujeito. Aqui a ênfase de Lacan estava no simbólico, sendo ele autônomo e determinante em relação ao imaginário e ao real, que eram tomados como registros secundários da experiência humana.

O simbólico domina o imaginário, que oferece resistência. Lacan relaciona sempre ao simbólico - no que chamo seu ponto de partida e que se estende por alguns anos - o registro da causa, da determinação fundamental: quando ele pensa apreender alguma coisa que rege os efeitos determinantes para o sujeito, ele o imputa ao simbólico. [...] O real puro é da ordem do dado, por exemplo, o dado do organismo. Mas comporta uma zona não indiferente que acontece no simbólico. De forma que, ao mesmo tempo em que Lacan pôde dizê-lo excluído, o real, nessa zona, parece sofrer os efeitos da causa simbólica, de modo indireto, pelo viés do imaginário. (MILLER, 2005, p. 95-96)

Esse é o momento mais conhecido de seu ensino, e esse aspecto fica bem caracterizado pela noção de que o significante é a morte da coisa. Ou seja, há uma anulação completa da coisa pela sua representação. A captura do real pelo símbolo é total, sendo que o que fica de fora da representação não tem valor de determinação para o sujeito. 
Durante essa fase inicial, Lacan foi presa da lógica do estádio do espelho, em que a satisfação pulsional está ligada à imagem que o sujeito tem do seu corpo no espelho. Essa imagem do corpo, completa, que destoa das sensações de conflito interno, gera um júbilo na criança, o que constitui a satisfação pulsional. Assim, a libido foi designada como habitando apenas o imaginário. Toda a libido ficava ligada à imagem do eu, na perspectiva do narcisismo, e na relação de objeto que se estende da imagem egoica para objetos especulares e retorna para o eu. Nesse domínio está o que Lacan denomina o pequeno outro, o outro semelhante, que comporta traços de identificação imaginária, como extensão do eu; e que também evoca uma relação de agressividade, a partir de uma lógica de exclusão, a lógica do "ou eu ou ele".

Esse estatuto do outro é fundamental para pensarmos a questão da intolerância à diferença. O outro só vale no que é igual a mim, é meu ideal ou me completa. No que destoa precisa ser excluído. Recorrendo a Freud, em seu texto Psicologia de grupo e a análise do ego:

\begin{abstract}
Nas antipatias e aversões indisfarçadas que as pessoas sentem por estranhos com que têm de tratar, podemos identificar a expressão do amor a si mesmo, do narcisismo. Esse amor a si mesmo trabalha para a preservação do indivíduo e comporta-se como se a ocorrência de qualquer divergência de suas próprias linhas de desenvolvimento envolvesse uma crítica delas e uma exigência de sua alteração. (FREUD, 1921, p. 129)
\end{abstract}

Isso é fundamentalmente diferente do Outro do registro simbólico, o qual Lacan chamou de "grande Outro" e escreveu com inicial maiúscula. Ele comporta a alteridade em termos de linguagem, num nível de assimetria em relação ao sujeito, e é marcado essencialmente por uma falta que o descompleta e que faz o sujeito levantar uma questão sobre o desejo, formulada como “O que o Outro quer de mim?”. Há educadores que ficam nessa posição - geralmente os que realizam a função materna, a função paterna e os seus substitutos - e, daí, podem fazer o sujeito se movimentar em relação à diferença.

Continuemos com o percurso de Lacan.

O fato é que a predominância do simbólico se tornou um empecilho teórico para ele, pois toma o sujeito num dinamismo que não se confirma enquanto fato da clínica. Aos poucos seus conceitos foram sendo reformulados para dar conta de um aspecto central da perspectiva freudiana do inconsciente: a satisfação ligada à pulsão de morte. Assim, a pulsão de morte incidiria sobre o conceito de desejo, que tratava a pulsão a partir do 
simbólico, e viria à cena o conceito de gozo, que faria referência à pulsão como fato do real.

Neste ponto, o aforismo de que o símbolo é a morte da coisa fica relativizado, pois algo da coisa sobrevive à anulação significante, ou seja, a operação simbólica deixa um resto, e é precisamente esse resto que vai insistir na cadeia significante e provocar repetição. Assim, o simbólico se constitui a partir de um elemento externo a ele, não sendo mais autônomo e determinante quanto aos outros registros, mas dependendo de algo que lhe é heterogêneo: o gozo, que advém do real.

Enquanto Lacan, anos a fio, desenvolveu a autonomia da lei simbólica, que nada deve a ninguém, justificável de um estudo puramente lógico, no seminário $\mathrm{O}$ avesso da psicanálise, ele formula o seguinte: "Existe uma relação primitiva do saber ao gozo". O que quer dizer: não existe autonomia do simbólico, que é heterônomo quanto ao gozo. (MILLER, 2005, p. 181)

A partir desse momento os três registros - real, simbólico e imaginário - são tomados com valor de igualdade, deixando o simbólico a sua posição de predominância. Dessa forma, o que é inassimilável pela representação, que diz respeito ao registro do real, equipara-se em importância aos registros que contam para sua operacionalidade com formas representacionais - o imaginário e o simbólico. É importante salientar que, nesse constructo teórico, o real se distingue da ideia de realidade, sendo esta uma articulação entre a significação simbólica e a padronização característica das imagens (ZIZEK; DALY; 2006, p. 13-14).

Essa virada indica que o que está fora da representação assume um valor fundamental para a própria existência da cadeia significante. O que, da coisa, não foi recoberto pelo símbolo insiste em retornar, em permanecer, em se fazer presente. Daí que certos significantes sejam condensadores de gozo para o sujeito, sejam meio de satisfação pulsional e, por isso, apareçam repetidamente na cadeia dos significantes. No entanto, a repetição, em psicanálise, causa diferença, já que um significante não se encerra em si, mas necessariamente remete a outro. No seminário 11 , Lacan diz que a repetição é constituída 
pela diversidade mais radical Ou seja, a repetição significante, causada por aquilo que está fora da representação, é produtora de diferença² .

É visível que essa dimensão do real tornou-se um conceito central para a teoria lacaniana, e, identificando-a à diferença, retomaremos nossa questão sobre a possibilidade de a ação educativa não segregá-la.

O ato educativo é social, se dá num laço entre educando e educador; é esse laço que modalizará o gozo, podendo segregá-lo ou visá-lo, para incidir sobre ele.

Os laços sociais foram formulados, inicialmente, por Lacan, a partir de quatro posições discursivas: do mestre, da histérica, da universidade e do analista, tendo ele, posteriormente, acrescentado a essas o discurso capitalista ${ }^{3}$. A educação se dá especialmente a partir do discurso do mestre. A característica fundamental desse discurso é que tudo tem que funcionar, custe o que custar. $\mathrm{O}$ (significante) mestre é o agente desse discurso, ele trabalha pela homogeneidade, estabelece ideais, impõe regras, faz cumprir a lei e não quer saber sobre a verdade do outro (no caso, o educando). Essa verdade é a que aponta para a divisão subjetiva, ou seja, diz que há algo que desconhecemos e tem efeito sobre nós, sobre o qual não temos controle absoluto. É a verdade do desejo. É o reconhecimento da castração e do limite do saber. $\mathrm{O}$ mestre não quer saber sobre nada disso, ele quer que as coisas andem, que o outro cumpra, realize, faça.

Dentro do processo pedagógico aparece uma outra versão desse discurso. Um discurso no qual o agente é o saber. A aplicação dos conhecimentos à criança visa torná-la sociável, adaptável, retirando seus aspectos excessivos e incontroláveis (ZIZEK, 2003, p. 173).

A educação se marca por esse lugar, e ele não é dispensável; lembremo-nos dos conselhos de Freud sobre a necessidade da coerção externa para que o sujeito possa ser algo mais do que exigência de satisfação. Mas é necessário dizer que o único caminho que o educando tem para lidar com sua verdade subjetiva nesses laços sociais é a sintomatização. É um certo lidar, não lidando; é a entrada no não querer saber nada disso.

Como alternativa a essas posições, encontramos um discurso em que o agente é um sujeito dividido, que sabe sobre a falta, sobre não abarcar tudo a partir do saber técnico.

\footnotetext{
${ }^{2}$ Consultar a esse respeito, especialmente, a sessão $\mathrm{V}$ do referido seminário.

${ }^{3}$ As modalidades discursivas foram formuladas por Lacan no seminário O Avesso da Psicanálise.
} 
Ele não se contenta com a certeza do mestre: questiona, quer saber mais sobre a realidade do desejo, sobre a incompletude, sobre a relação sexual. É aqui que o desejo de saber tem lugar, e a diferença não leva ao silêncio.

Esse é o discurso da histérica, um discurso que não segrega a diferença, que a toma para produzir algo a partir dela, para inventar um saber, levando em conta a verdade do sujeito, do desejo, do sexo, da morte.

É por esse entrelaçamento dos laços sociais na educação que a diferença pode produzir algo novo, que provoque o sujeito a criar.

\section{PARA LANÇAR UMA NOVA QUESTÃO}

Um encerramento sempre é precoce. É por isso que sempre resta algo para ser relançado.

Dizer que é preciso fazer falar quando a diferença é segregada pelo silêncio não basta. Dizer que é preciso causar um enigma onde há somente um gozo com o não saber é insuficiente. Fica, ainda, a advertência freudiana de que a educação é uma empreitada de risco, que não possui medida certa. Que ela é necessária à constituição do ser humano, mas contém algo de impossível, já que seus efeitos só serão apreendidos posteriormente e podem ser bem distantes do seu projeto inicial.

Assim, cabe considerarmos que o saber constituído por cada sujeito sobre o ato de educar sempre será passível de falha, porém sempre será um meio para fazer frente à impossibilidade dessa tarefa.

\section{REFERÊNCIAS}

FREUD, Sigmund. Além do princípio de prazer. In: Edição standard das obras psicológicas completas de Sigmund Freud. Rio de Janeiro: Imago, 1976 (1920). p.13-85. (v. 18).

Novas conferências introdutórias sobre psicanálise: conferência XXXIV. In: Edição standard das obras psicológicas completas de Sigmund Freud. Rio de Janeiro: Imago, 1976 (1933). p. 167-191. (v. 22). 
O inconsciente. . Edição standard das obras psicológicas completas de Sigmund Freud. Rio de Janeiro: Imago, 1976 (1915). p.185-245. (v. 14).

O interesse científico da psicanálise. In: Edição standard das obras psicológicas completas de Sigmund Freud. Rio de Janeiro, RJ: Imago, 1976 (1913). p.197-226. (v. 13).

O futuro de uma ilusão. In: Edição standard das obras psicológicas completas de Sigmund Freud. Rio de Janeiro, RJ: Imago, 1976 (1927). p. 13-71. (v.21).

. O mal-estar na civilização. In: Edição standard das obras psicológicas completas de Sigmund Freud. Rio de Janeiro: Imago, 1976 (1930). p. 75-171. (v.21). Psicologia de grupo e a análise do ego. In: . Edição standard das obras psicológicas completas de Sigmund Freud. Rio de Janeiro: Imago, 1976 (1921). p. 89179. (v.18).

LACAN, Jacques. O seminário, livro 11: os quatro conceitos fundamentais da psicanálise. Rio de Janeiro, RJ: Jorge Zahar, 2008.

MILLER, Jacques-Alain. Silet: os paradoxos da pulsão, de Freud a Lacan. Rio de Janeiro, RJ: Zahar, 2005.

ZIZEK, Slavoj. Eles não sabem o que fazem: o sublime objeto da ideologia. Rio de Janeiro, RJ: Zahar, 2003.

ZIZEK, Slavoj; DALY, Glyn. Arriscar o impossível: conversas com Zizek. São Paulo: Martins Fontes, 2006.

Esta pesquisa foi financiada pela Fundação de Amparo à Pesquisa do Estado de São Paulo-FAPESP. 